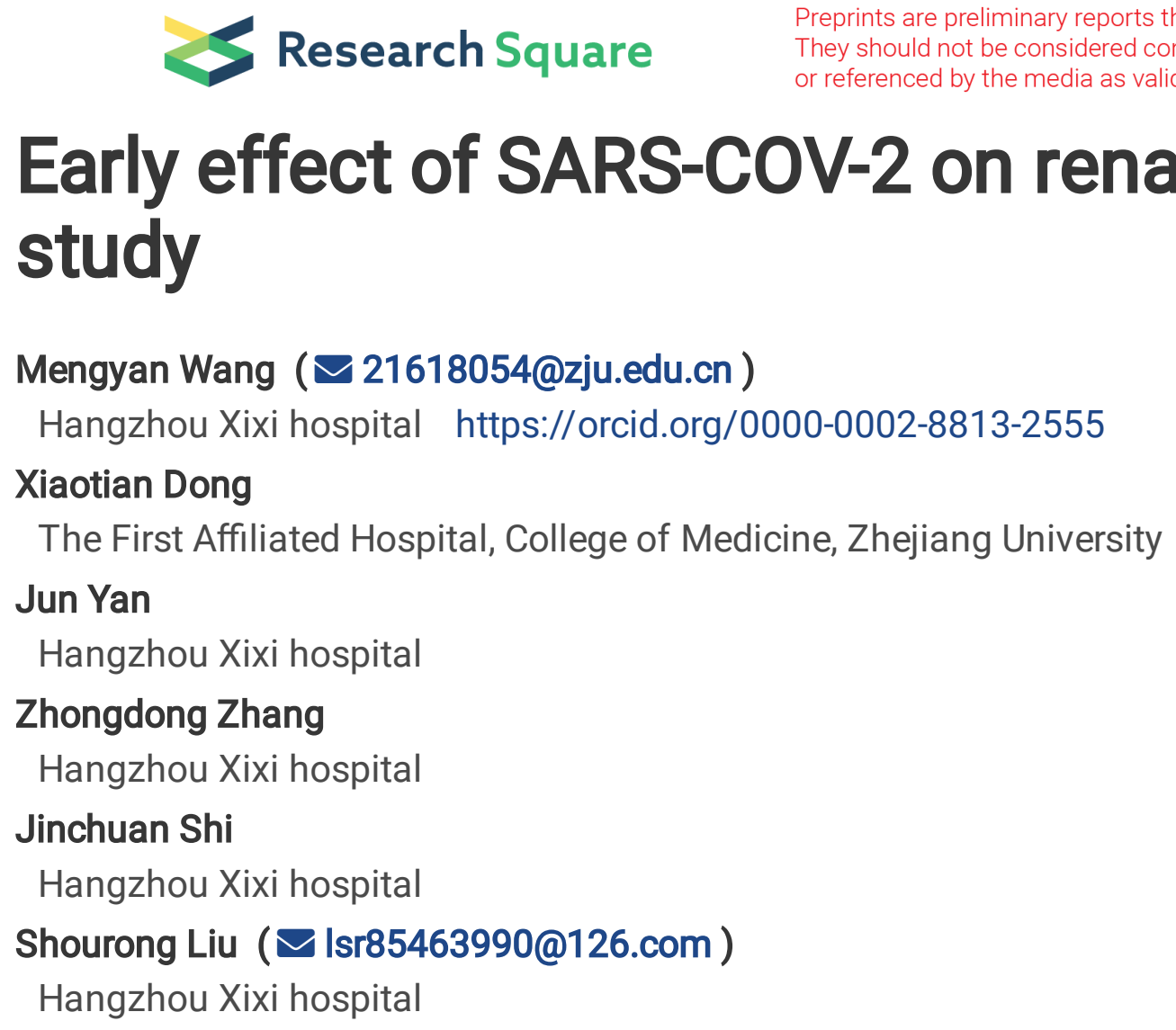

\title{
Early effect of SARS-COV-2 on renal tubule: a pilot study
}

\section{Research Article}

Keywords: COVID-19, clinical characteristics, renal tubular injury

Posted Date: May 12th, 2020

DOl: https://doi.org/10.21203/rs.3.rs-28591/v1

License: (c) (i) This work is licensed under a Creative Commons Attribution 4.0 International License. Read Full License 


\section{Abstract}

Objective: To explore the early clinical characteristics of coronavirus disease 2019 (COVID-19) and provide a reference for the early prevention and treatment of the disease.

Methods: We collected and analyzed demographic data, medical history, exposure history, underline diseases, symptoms, signs, laboratory data, chest computed tomographic (CT) scans, and treatment measures of COVID-19 patients admitted to the Sixth People's Hospital of Hangzhou from January 20 to February 23, 2020.

Results: Among 51 confirmed COVID-19 patients included in this study, 7.8\% (4/51) patients were severe and $45.1 \%$ (23/51) were male. Median age was 43 years (IQR, 23). Fever $(54.9 \%, 28 / 51)$ and cough $(52.9 \%, 27 / 51)$ were the main symptoms. $74.5 \%(38 / 51)$ patients had a history of exposure and $17.6 \%$ $(9 / 51)$ patients had a history of hypertension. Importantly, most $(60.8 \%, 31 / 51)$ patients had an increase of urine $\beta 2$ microglobulin. In addition, the inflammation indexes (C-reactive protein and serum amyloid $A$ ) of patients with elevated urine $\beta 2$ microglobulin were significantly increased $(p=0.017$ and $p=0.049$ ) and lymphocytes count was significantly reduced $(p=0.012)$, compared with patients with normal urine $\beta 2$ microglobulin. Correlation analysis showed that urine $\beta 2$ microglobulin was positively correlated with C-reactive protein and serum amyloid A; but negatively correlated with lymphocytes count.

Conclusions: COVID-19 patients have obvious symptoms of lung injury, but the occurrence of early renal tubular injuries has to be monitored vigilantly.

\section{Introduction}

The worldwide spread of COVID-19 (Coronavirus disease 2019『COVID-19) has become a global health problem. In late December 2019, this previously unknown acute respiratory disease was first reported in Wuhan, Hubei Province, China ${ }^{1}$. Studies on SARS-Cov-2 transmission confirmed human to human transmission 2,3. SARS-Cov-2 had similar sequences (about 79\%) with severe acute respiratory syndrome coronavirus (SARS-CoV) and about $50 \%$ similarity with Middle East respiratory syndrome coronavirus (MERS-CoV) ${ }^{4}$. Since January 2020 , SARS-Cov-2 has rapidly spread to most parts of China. And now, the worldwide outbreak of SARS-Cov-2 indicated that every detail cannot be ignored. Previous studies had shown that SARS-CoV-2 can affect multiple organs, and its receptor angiotensin-converting enzyme 2 (ACE2) highly expressed in the heart, liver, kidney, testes, and intestines ${ }^{5}$. Guangzhou Daily reported that Zhong et al had found SARS-Cov-2 RNA in urine and feces. Moreover, compared with healthy controls, some urine biochemical parameters have been found different in COVID-19 patients, urine glucose and proteinuria may be helpful for distinguishing of COVID-19 severity ${ }^{6}$. It is necessary and value to look for other than lung damages in COVID-19 patients. In order to further understand the early organ damage in COVID-19 patients, target organs related indicators were analyzed.

\section{Methods}




\section{Study Population}

This study retrospectively included COVID-19 patients admitted to the Sixth People's Hospital of Hangzhou from January 20 to February 23, 2020. The diagnosis of COVID-19 was confirmed according to the interim guidelines of the World Health Organization ${ }^{7}$. Patients with other viral infections or/and renal insufficiency were excluded. Finally, 51 patients who had complete data were enrolled.

The severity of COVID-19 was defined according to the Sixth Edition Guidelines for the Diagnosis and Treatment of Coronavirus Pneumonia. Mild pneumonia: The patients had mild clinical symptoms and normal imaging. Moderate pneumonia: The patients had a fever, respiratory symptoms, and/or other symptoms, and imaging showed pneumonia. Severe pneumonia: Meet any of the following conditions ( 1 . Respiratory distress, breathing rate $\geq 30 / \mathrm{min} ; 2$. Calm state, oxygen saturation $\leq 93 \% ; 3$. PaO2/FiO2 $\leq$ $300 \mathrm{mmHg}$, and/or within 24 to 48 hours Lung infiltration > 50\%).

\section{Data Collection}

Data was collected from electronic medical records and reviewed by a team of physicians. The recorded information includes demographic data, medical history, contact history, underlying diseases, symptoms, signs, laboratory test results, chest computed tomography (CT) and treatment measures (antiviral therapy, glucocorticoid therapy, Chinese medicine treatment, symptomatic treatment). The exposure history before onset, including the time of close contact with a confirmed or suspected case. Laboratory test results included a complete blood cells count at admission, serum and urine biochemistry indexes, coagulation and heart function indicators, C-reactive protein, serum amyloid A, procalcitonin, and blood gas analysis.

\section{Statistical analysis}

Continuous data was compared by Mann-Whitney U test or Student's t test and expressed as median (IQR). Discrete data was compared by Fisher's exact test and expressed as frequencies (percentages). Correlation analysis was conducted by Pearson or Spearman correlation analysis. All analyses were performed using SPSS version 19 (SPSS, Armonk, New York, USA), and $p<0.05$ was considered statistically significant.

\section{Results}

\section{Clinical characteristics of patients with COVID-19}

A total of 51 confirmed COVID-19 patients (Table 1) were included in this study. The median age was 43 years (IQR, 23). 23 (45.10\%) patients were between 30-50 years old, and 19 (37.25\%) patients were 50 years old or older. $28(54.90 \%)$ patients were female. The results showed that fever $(54.90 \%)$ and cough 
(52.94\%) were the main symptoms of the disease, and fatigue (17.64\%), expectoration (21.57\%), myalgia (7.84\%), sore throat $(13.72 \%)$, chest tightness $(11.76 \%)$, diarrhea $(7.84 \%)$ were common symptoms of the disease. $38(74.51 \%)$ patients had a history of exposure. 9 (17.64\%) patients had hypertension. 37 (72.55\%) patients had lesions in both lungs. All patients received anti-viral therapy with interferon alpha inhalation (5 million $\mathrm{U})$ + lopinavir/ritonavir (2 tablets BID) + Arbidol (0.2g TID), of which 13 patients discontinued due to side effects. 42 (82.35\%) patients received Chinese medicine therapy. 29 (56.86\%) patients received therapy of preventive liver protection. 29 (56.86\%) patients received acetylcysteine effervescent tablets therapy. $15(29.41 \%)$ patients received gamma globulin therapy. 8 (15.69\%) patients received albumin therapy. 12 (23.53\%) patients received glucocorticoid therapy. 27 (52.94\%) received microbial preparations. $21(41.17 \%)$ patients received antibiotic treatment.

\section{Early analysis of SARS-CoV-2 related target organ indicators}

By analyzing laboratory indicators of related target organs in blood at admission. We found that urine $\beta 2$ microglobulin was elevated in $31(60.78 \%)$ patients and it's median $(406.9 \mu \mathrm{g} / \mathrm{L}(\mathrm{IQR}, 1027.1))$ was higher than the normal range. 18 (35.29\%) patients had elevated N-acetyl- $\beta$-D-glucosidase; 13 (25.49\%) patients had elevated total urine protein; serum $\mathrm{K}^{+}$was decreased in $10(19.61 \%)$ patients, and serum creatinine was increased in $10(19.61 \%)$ patients. 8 (15.69\%) patients experienced a decrease in oxygen partial pressure; and 7 (13.73\%) patients had abnormal carbon dioxide partial pressure. ALT was increased in 9 (17.65\%) patients; AST was increased in 12 (23.53\%) patients; 3 patients had elevated TB; 8 patients had increased DB; and 10 patients had increased GGT. CK was elevated in $5(9.80 \%)$ patients and BNP was elevated in only one patient (Table 2).

\section{Analysis of urine $\beta 2$ microglobulin}

The median of SAA (75.5 mg/L (IQR, 87.3)) was significantly higher in elevated urine $\beta 2$ microglobulin group $(n=31)$, compared with normal urine $\beta 2$ microglobulin group $(n=20)(p=0.049)$. Compared with normal urine $\beta 2$ microglobulin group, CRP and LDH were higher in elevated urine $\beta 2$ microglobulin group $(p=0.017, p=0.001)$. In addition, the lymphocytes count of the elevated urine $\beta 2$ microglobulin group was lower than that of normal urine $\beta 2$ microglobulin group $(p=0.012)$. There were 3 severe patients in the elevated urine $\beta 2$ microglobulin group and 1 severe patient in the normal group (Table 3 ). Correlation analysis found that urine $\beta 2$ microglobulin was positively correlated with CRP (Figure 1, $r=0.423, p=$ 0.003 ) and positively correlated with SAA (Figure $2, r=0.315, p=0.029$ ), and negatively correlated with the lymphocytes count (Figure $3, r=-0.292, p=0.044$ ).

\section{Discussion}


The findings of our study were similar to previous study ${ }^{8}$. COVID-19 patients in our study was between 5-89 years old, and the main symptoms were fever and dry cough. All patients received antiviral therapy, and received symptomatic treatment such as traditional Chinese medicine, liver protection, expectorant and some patients were treated with gamma globulin, hormones, albumin treatments. The overall prognosis of patients in Hangzhou was better than in Wuhan 9,10 because there were $17 \%-32 \%$ patients developed severe cases and $11 \%-15 \%$ died in Wuhan, but there were no deaths and only $7.8 \%$ severe cases in our study. And the previous study ${ }^{8}$ displayed the similar results with us.

The pathogen of COVID-19 is SARS-CoV-2, which belongs to the Betacoronavirus genus similar to SARS-CoV and MERS-CoV ${ }^{11}$. The ACE2 (angiotensin-converting enzyme 2) gene encodes angiotensinconverting enzyme 2 , which had been found as a receptor for SARS-CoV and human respiratory coronavirus NL63. Recent research suggested that ACE2 may be a receptor for SARS-CoV-2 to infect hosts ${ }^{4,12}$. Studies have found that SARS-Cov-2 enters the cell by binding coronavirus spike glycoprotein with the human ACE2 receptor ${ }^{13}$. Studies showed that $83 \%$ ACE2 is expressed on alveolar epithelial type II cells, which could explain why the lung is the most vulnerable target organ. In addition, the expression of ACE2 receptors is also found in many extrapulmonary tissues, including the heart, kidney, endothelium, and intestines ${ }^{14}$. Our results showed that some patients had abnormal indicators of heart, liver, and kidney in early disease. Among them, indicator of renal tubule was mostly common abnormal. Recent research on single-cell RNA sequencing data showed that ACE2 was abundantly expressed in proximal tubule cells at the RNA level, and was consistent with single-cell RNA sequencing data at the protein level 15 . Our study showed that $60.78 \%$ patients with COVID-19 had elevated urine $\beta 2$ microglobulin, and the increased urine $\beta 2$ microglobulin can be explained by renal tubule absorption dysfunction, suggesting that SARS-Cov-2 may result in renal tubule damage. The mechanism may be consistent with the above studies.

A recent study found that the prevalence of kidney damage (hematuria, proteinuria, and renal insufficiency) in patients with COVID-19 was high. Acute kidney injury occurred in $3.2 \%$ patients, and renal damage indicators had a high correlation with in-hospital mortality risk ${ }^{16}$. Our results showed that $19.61 \%$ patients have elevated serum creatinine, which is close to the data in this study. In addition, the results of our study showed that the increase of urine $\beta 2$ microglobulin was related to systemic inflammation and immune factors. It was consistent with previous studies that found that the pathological changes of COVID-19 were related to the inflammatory response and immune factors of cytokine bursts ${ }^{17,18}$.

There were some deficiencies in our study. First, the number of cases was not enough and a larger sample size was needed to support the study. Secondly, due to the limitation of conditions, analysis of cytokines and immune cell subsets could not be performed to further analyze the factors related to renal tubular injury. Furthermore, no long-term follow-up was performed to observe the target organ recovery and possible progression of the patients. 
In summary, our study found that except for the lung injury, relevant target organs were also injured in early disease. And most patients had tubular damage. And this damage may be related to systemic inflammation and immunity. COVID-19 patients had obvious symptoms of lung injury, but the occurrence of early renal tubular injuries has to be monitored vigilantly.

\section{Declarations}

\section{Ethics approval}

All patients provided written informed consent and this study was approved by Ethics Committee of Xixi Hospital of Hangzhou in China. All procedures and methods were performed in accordance with the relevant international guidelines and regulations in order to reduce physical discomfort of the subjects.

\section{Availability of data and materials}

The datasets used and/or analysed during the current study are available from the first author on reasonable request.

\section{Funding Source}

This study supported by Research project on the prevention and treatment of COVID-19 in Hangzhou.

\section{Conflict of interest}

The authors declare that they have no competing interests.

\section{Acknowledgements}

We would like to thank the native English speaking scientists of Elixigen Company (Huntington Beach, California) for editing our manuscript.

\section{References}

1. Lu, H., Stratton, C. W. \& Tang, Y. W. Outbreak of pneumonia of unknown etiology in Wuhan, China: The mystery and the miracle. J Med Virol 92, 401-402 (2020).

2. Chan, J. F. et al. A familial cluster of pneumonia associated with the 2019 novel coronavirus indicating person-to-person transmission: a study of a family cluster. Lancet 395, 514-523 (2020).

3. Phan, L. T. et al. Importation and Human-to-Human Transmission of a Novel Coronavirus in Vietnam. $N$ Engl J Med 382, 872-874 (2020).

4. Lu, R. et al. Genomic characterisation and epidemiology of 2019 novel coronavirus: implications for virus origins and receptor binding. Lancet 395, 565-574 (2020). 
5. Guan, G. W. et al. [Exploring the mechanism of liver enzyme abnormalities in patients with novel coronavirus-infected pneumonia]. Zhonghua gan zang bing za zhi = Zhonghua ganzangbing zazhi = Chinese journal of hepatology 28, E002 (2020).

6. Liu, R. et al. The value of urine biochemical parameters in the prediction of the severity of coronavirus disease 2019. Clin Chem Lab Med (2020).

7. Wu, J. et al. Clinical Characteristics of Imported Cases of COVID-19 in Jiangsu Province: A Multicenter Descriptive Study. Clin Infect Dis (2020).

8. Xu, X. W. et al. Clinical findings in a group of patients infected with the 2019 novel coronavirus (SARSCov-2) outside of Wuhan, China: retrospective case series. BMJ 368, m606 (2020).

9. Wang, D. et al. Clinical Characteristics of 138 Hospitalized Patients With 2019 Novel CoronavirusInfected Pneumonia in Wuhan, China. JAMA (2020).

10. Chen, N. et al. Epidemiological and clinical characteristics of 99 cases of 2019 novel coronavirus pneumonia in Wuhan, China: a descriptive study. Lancet 395, 507-513 (2020).

11. Gu, H., Chu, D. K., Peiris, J. S. M. \& Poon, L. L. Multivariate Analyses of Codon Usage of SARS-CoV-2 and other betacoronaviruses. bioRxiv (2020).

12. Yan, R. et al. Structural basis for the recognition of the SARS-CoV-2 by full-length human ACE2. Science (2020).

13. Walls, A. C. et al. Structure, Function, and Antigenicity of the SARS-CoV-2 Spike Glycoprotein. Cell (2020).

14. Zhang, H., Penninger, J. M., Li, Y., Zhong, N. \& Slutsky, A. S. Angiotensin-converting enzyme 2 (ACE2) as a SARS-CoV-2 receptor: molecular mechanisms and potential therapeutic target. Intensive Care Med, 1$5(2020)$.

15. Deng, Y. Y., Zheng, Y., Cai, G. Y., Chen, X. M. \& Hong, Q. Single-cell RNA sequencing data suggest a role for angiotensin-converting enzyme 2 in kidney impairment in patients infected with 2019-nCoV. Chin Med $J$ (Engl) (2020).

16. Cheng, Y. et al. Kidney impairment is associated with in-hospital death of COVID-19 patients. medRxiv (2020).

17. Xu, Z. et al. Pathological findings of COVID-19 associated with acute respiratory distress syndrome. The Lancet Respiratory medicine (2020).

18. Luo, W. et al. Clinical Pathology of Critical Patient with Novel Coronavirus Pneumonia (COVID-19). (2020). 


\section{Tables}

Table 1: Clinical characteristics of COVID-19 patients. 


\begin{tabular}{|c|c|}
\hline Characteristics & Patients $(\mathrm{n}=51)$ \\
\hline Age, years, Median (IQR) & $43(23)$ \\
\hline$<30$ years & $9(17.65 \%)$ \\
\hline $30-50$ years & $23(45.1 \%)$ \\
\hline$\geq 50$ years & $19(37.25 \%)$ \\
\hline Gender $(\mathrm{M} / \mathrm{F})$ & $23 / 28(45.1 \% / 54.9 \%)$ \\
\hline \multicolumn{2}{|l|}{ Signs and symptoms } \\
\hline Fever & $28(54.9 \%)$ \\
\hline Cough & $27(52.94 \%)$ \\
\hline Myalgia & $4(7.84 \%)$ \\
\hline Expectoration & $11(21.57 \%)$ \\
\hline Chest tightness & $6(11.76 \%)$ \\
\hline Diarrhea & $4(7.84 \%)$ \\
\hline Sore throat & $7(13.72 \%)$ \\
\hline Fatigue & $9(17.64 \%)$ \\
\hline Exposure history & $38(74.51 \%)$ \\
\hline \multicolumn{2}{|l|}{ Underline disease } \\
\hline Hypertension & $9(17.64 \%)$ \\
\hline Tumor & $2(3.92 \%)$ \\
\hline Diabetes & $2(3.92 \%)$ \\
\hline Depression & $1(1.96 \%)$ \\
\hline Chronic hepatitis B & $2(3.92 \%)$ \\
\hline Bilateral distribution of patchy shadows or ground glass opacity & $37(72.55 \%)$ \\
\hline \multicolumn{2}{|l|}{ Treatment } \\
\hline $\begin{array}{l}\text { interferon alpha ( } 5 \text { million } \mathrm{U})+ \text { lopinavir/ritonavir (2 tablets } \\
\text { BID) + Arbidol (0.2g TID) }\end{array}$ & $51(100 \%)$ \\
\hline $\begin{array}{l}\text { Glucocorticoid+ Gamma globulin therapy+ Antibiotic treatment+ } \\
\text { Albumin therapy }\end{array}$ & $2(3.92 \%)$ \\
\hline Glucocorticoid+ Gamma globulin therapy+ Antibiotic treatment & $3(5.88 \%)$ \\
\hline
\end{tabular}


Glucocorticoid+ Albumin therapy+ Antibiotic treatment

$2(3.92 \%)$

Glucocorticoid +Gamma globulin therapy

$8(15.69 \%)$

Albumin therapy+ Antibiotic treatment

$5(9.8 \%)$

Gamma globulin therapy+ Antibiotic treatment

$7(13.73 \%)$

Gamma globulin therapy

$15(29.41 \%)$

Glucocorticoid

$12(23.53 \%)$

Therapy of preventive liver protection.

$29(56.86 \%)$

Acetylcysteine effervescent tablets

$29(56.86 \%)$

Chinese medicine

$42(82.35 \%)$

Microbial preparations

$27(52.94 \%)$

Antibiotic treatment

$21(41.17 \%)$

Albumin therapy

$8(15.69 \%)$

Data are median (IQR), no. (\%).

Table 2. Laboratory indicators of related target organs 


\begin{tabular}{|c|c|c|}
\hline Variables & Normal range & Patients $(n=51)$ \\
\hline \multicolumn{3}{|l|}{ Lungs } \\
\hline PaO2, Median (IQR) & 83-108 mmHg & $97.2(50.9)$ \\
\hline reduced & & $8(15.69 \%)$ \\
\hline PaCO2, Median (IQR) & $35-45 \mathrm{mmHg}$ & $42.2(5.0)$ \\
\hline increased & & $5(9.80 \%)$ \\
\hline reduced & & $2(3.92 \%)$ \\
\hline \multicolumn{3}{|l|}{ Heart } \\
\hline BNP, Median (IQR) & $0-450 \mathrm{pg} / \mathrm{ml}$ & 33(98.5) \\
\hline increased & & $1(1.96 \%)$ \\
\hline CK, Median (IQR) & 24-170 U/L & $65(53.5)$ \\
\hline increased & & $5(9.80 \%)$ \\
\hline \multicolumn{3}{|l|}{ Liver } \\
\hline ALT, Median (IQR) & $7-40 \mathrm{U} / \mathrm{L}$ & $24.0(13)$ \\
\hline increased & & $9(17.65 \%)$ \\
\hline AST, Median (IQR) & $13-35 \mathrm{U} / \mathrm{L}$ & $17.0(20)$ \\
\hline increased & & $12(23.53 \%)$ \\
\hline TB, Median (IQR) & $3.42-20.52 \mu \mathrm{mol} / \mathrm{L}$ & $8.88(10.14)$ \\
\hline increased & & $3(5.88 \%)$ \\
\hline DB, Median (IQR) & $0-6.84 \mu \mathrm{mol} / \mathrm{L}$ & $3.96(2.99)$ \\
\hline increased & & $8(15.69 \%)$ \\
\hline GGT, Median (IQR) & 7-45 U/L & $22(30)$ \\
\hline increased & & $10(19.61 \%)$ \\
\hline AKP, Median (IQR) & 47-406 U/L & $69.0(29.0)$ \\
\hline increased & & 0 \\
\hline \multicolumn{3}{|l|}{ Kidney } \\
\hline Serum creatinine, Median (IQR) & $41-81 \mu \mathrm{mol} / \mathrm{L}$ & $70.0(29.0)$ \\
\hline increased & & $10(19.61 \%)$ \\
\hline Urine $\beta 2$ microglobulin, Median (IQR) & $100.00-300.00 \mu \mathrm{g} / \mathrm{L}$ & $406.9(1027.1)$ \\
\hline increased & & $31(60.78 \%)$ \\
\hline
\end{tabular}




\begin{tabular}{lll}
\hline Variables & Normal range & Patients $(\mathrm{n}=51)$ \\
\hline Urine creatinine, Median (IQR) & $2470-19200 \mu \mathrm{mol} / \mathrm{L}$ & $9526(10643.5)$ \\
increased & & $3(5.88 \%)$ \\
reduced & $0.00-11.50 \mathrm{U} / \mathrm{L}$ & $9.12(7.52)$ \\
NAD, Median (IQR) & & $18(35.29 \%)$ \\
increased & $0.00-15.00 \mathrm{mg} / \mathrm{L}$ & $6.6(11.33)$ \\
Urine microalbumin, Median (IQR) & $12(23.53 \%)$ \\
increased & & $55(80.2)$ \\
Total urine protein, Median (IQR) & $0.0-100.0 \mathrm{mg} / \mathrm{L}$ & $13(25.49 \%)$ \\
increased & & $3.72(0.58)$ \\
K+, Median (IQR) & $3.5-5.3 \mathrm{mmol} / \mathrm{L}$ & $10(19.61 \%)$ \\
reduced & & \\
\hline
\end{tabular}

Abbreviations: $\mathrm{PaO} 2$, partial pressure of oxygen; $\mathrm{PaCO} 2$, partial pressure of carbon dioxide; BNP, B-type natriuretic peptide; CK, creatine kinase; ALT, Alanine aminotransferase; AST, Aspartate aminotransferase; TB, Total bilirubin; DB, Direct bilirubin; GGT, Glutamyl transferase; AKP, Alkaline phosphatase; NAD, N-acetyl- $\beta$-Dglucosidase. Data are median (IQR), no. (\%).

Table 3. Comparison of related indexes of elevated urine $\beta 2$ microglobulin group and normal urine $\beta 2$ microglobulin group. 


\begin{tabular}{|c|c|c|c|c|}
\hline & $\begin{array}{l}\text { Normal } \\
\text { range }\end{array}$ & $\begin{array}{l}\text { Elevated urine } \beta 2 \\
\text { microglobulin }(n=31)\end{array}$ & $\begin{array}{l}\text { Normal urine } \beta 2 \\
\text { microglobulin }(n=20)\end{array}$ & $\begin{array}{l}\mathrm{P} \\
\text { value }\end{array}$ \\
\hline Age, years & & $50.3 \square 20.3 \square$ & $40.3 \square 25.5 \square$ & 0.247 \\
\hline Severe cases & & 3 & 1 & 1.0 \\
\hline $\mathrm{CRP}, \mathrm{mg} / \mathrm{L}$ & $0-10$ & $8.5(22.02)$ & $0.41(28.5)$ & 0.017 \\
\hline $\mathrm{SAA}, \mathrm{mg} / \mathrm{L}$ & $0-10$ & 75.5(87.3) & $13.0(141.5)$ & 0.049 \\
\hline $\mathrm{PCT}, \mathrm{ng} / \mathrm{ml}$ & $0-0.5$ & $0.028(0.014)$ & $0.026(0.036)$ & 0.053 \\
\hline Lymphocyte & $1.10-$ & $1.15(0.53)$ & $1.38(0.73)$ & 0.012 \\
\hline counts, $10^{\wedge} 9 / \mathrm{L}$ & 3.20 & & & \\
\hline WBC,10^9/L & $3.5-9.5$ & $5.01(1.89)$ & $6.12(1.88)$ & 0.721 \\
\hline Hemoglobin, g/L & $115-150$ & $133.5(27.5)$ & $154(18.5)$ & 0.985 \\
\hline $\begin{array}{l}\text { Urine creatinine, } \\
\mu \mathrm{mol} / \mathrm{L}\end{array}$ & $\begin{array}{l}2470- \\
19200\end{array}$ & 12539.0ロ77351.3₫ & 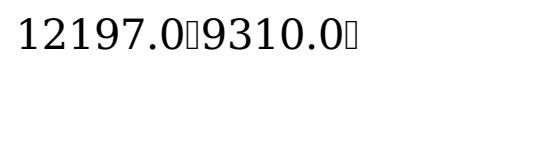 & 0.036 \\
\hline NAG, U/L & $\begin{array}{l}0.00- \\
11.50\end{array}$ & 12.61ロ12.33凸 & $8.88 \square 3.75 \square$ & 0.001 \\
\hline $\begin{array}{l}\text { Total urine } \\
\text { protein, } \mathrm{mg} / \mathrm{L}\end{array}$ & $\begin{array}{l}0.0- \\
100.0\end{array}$ & 92.2₫113.3ロ & $37.6 \square 29.9 \square$ & $<0.001$ \\
\hline $\begin{array}{l}\text { Urine } \\
\text { microalbumin, } \\
\mathrm{mg} / \mathrm{L}\end{array}$ & $\begin{array}{l}0.00- \\
15.00\end{array}$ & $10.64 \square 13.22 \square$ & $3.5 \square 3.2 \square$ & $<0.001$ \\
\hline $\mathrm{LDH}, \mathrm{U} / \mathrm{L}$ & $120-250$ & $200.5(77.3)$ & 178.0(129.0) & 0.001 \\
\hline AST, U/L & $13-35$ & $15.5(10.5)$ & $14.0(10.0)$ & 0.018 \\
\hline $\mathrm{ALT}, \mathrm{U} / \mathrm{L}$ & $7-40$ & $23.5(10.0)$ & $17.0(10.5)$ & 0.024 \\
\hline $\begin{array}{l}\text { Serum } \\
\text { creatinine }\end{array}$ & $41-81$ & $59.0 \square 23.0 \square$ & $79.0 \square 9.5 \square$ & 0.530 \\
\hline $\mathrm{K}+, \mathrm{mmol} / \mathrm{L}$ & $3.5-5.3$ & $3.89 \square 0.83 \square$ & $3.92 \square 0.92 \square$ & 0.297 \\
\hline $\mathrm{CK}, \mathrm{U} / \mathrm{L}$ & $24-170$ & $59.5 \square 20.0 \square$ & $51.0 \square 66.0 \square$ & 0.550 \\
\hline $\mathrm{BNP}, \mathrm{pg} / \mathrm{ml}$ & $0-450$ & 83.5๑103.25ロ & $15.0 \square 28.0 \square$ & 0.221 \\
\hline $\begin{array}{l}\text { Lactic acid, } \\
\mathrm{mmol} / \mathrm{L}\end{array}$ & $0.7-2.1$ & $1.4 \square 0.75 \square$ & $2.0 \square 1.30 \square$ & 0.077 \\
\hline
\end{tabular}




\begin{tabular}{llllll}
\hline & Normal & Elevated urine & $\beta 2$ & Normal urine & $\beta 2$ \\
& range & microglobulin(n=31) & microglobulin(n=20) & value \\
\hline D-dimer, mg/L & $0-0.55$ & $0.47(2.41)$ & $0.16(0.24)$ & 0.144 \\
$\mathrm{PaO} 2, \mathrm{mmHg}$ & $83-108$ & $96.9(25.8)$ & $85.2(113.4)$ & 0.431 \\
\hline
\end{tabular}

Abbreviations: CRP, C-reactive protein; SAA, serum amyloid A; PCT, procalcitonin; WBC, white blood cell count; LDH, lactate dehydrogenase. Data are median (IQR), p values comparing Elevated urine $\beta 2$ microglobulin group and Normal urine $\beta 2$ microglobulin group are from Fisher's exact test, or Mann-Whitney U test.

\section{Figures}

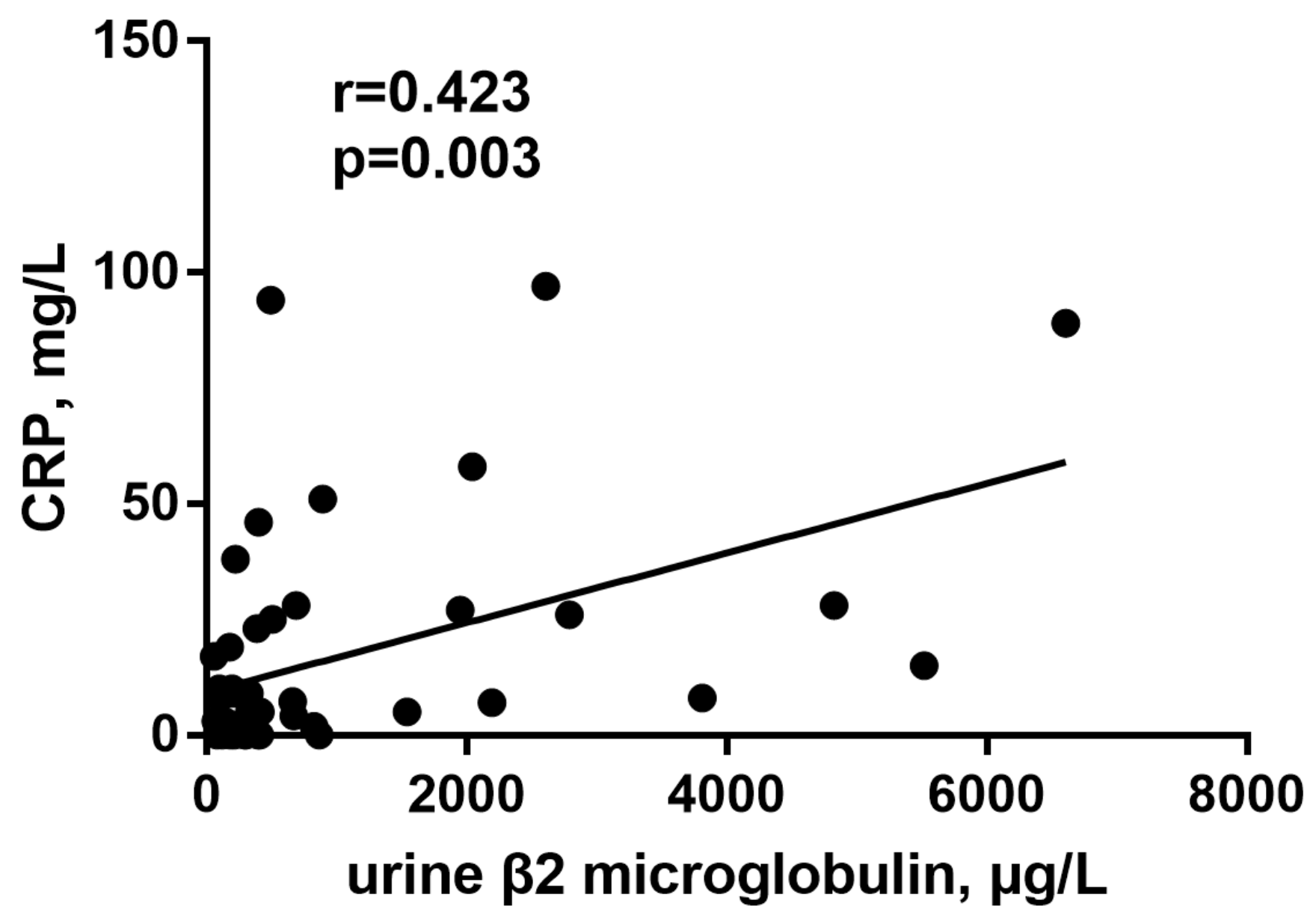

Figure 1 
Correlation analysis between urine $\beta 2$ microglobulin and CRP. Correlation analysis of urine $\beta 2$ microglobulin with CRP. $r=0.423, p=0.003$.

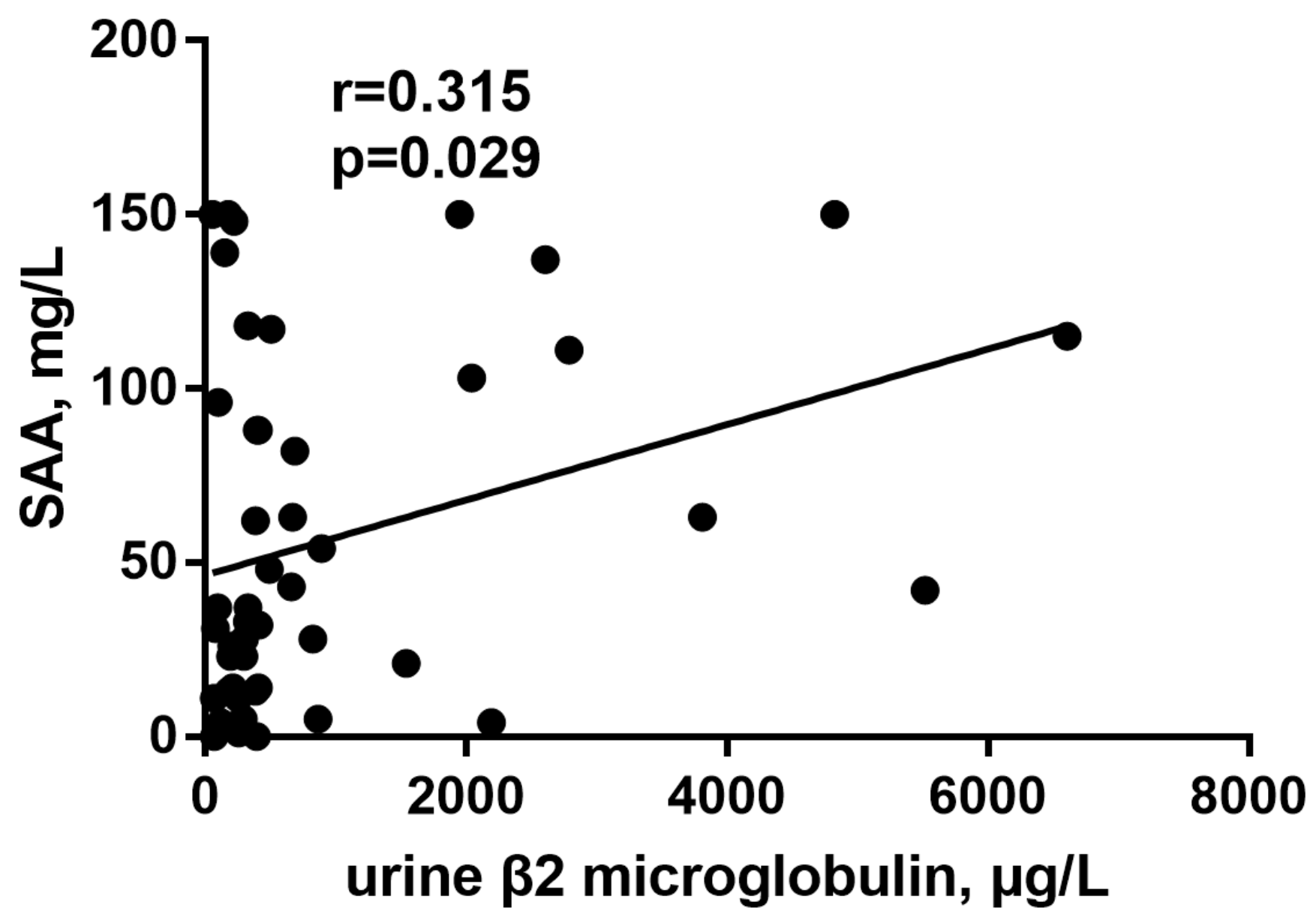

Figure 2

Correlation analysis between urine $\beta 2$ microglobulin and SAA. Correlation analysis of urine $\beta 2$ microglobulin with SAA. $r=0.315, p=0.029$. 


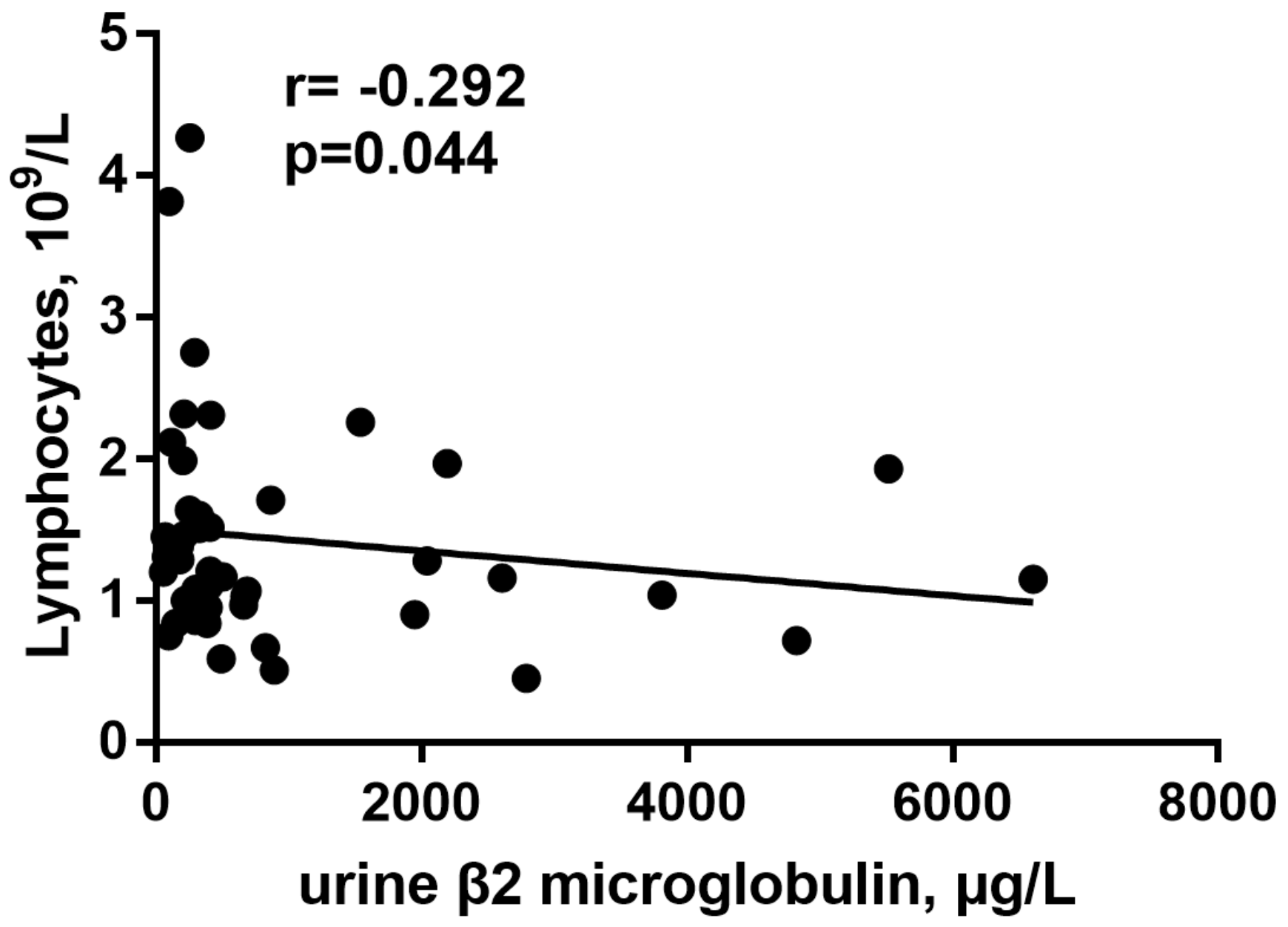

Figure 3

Correlation analysis between urine $\beta 2$ microglobulin and lymphocyte counts. Correlation analysis of urine $\beta 2$ microglobulin with the lymphocytes count. $r=-0.292, p=0.044$. 